\title{
Chromatin changes predict recurrence after radical prostatectomy
}

\author{
Tarjei S Hveem 1,2,3,6, Andreas Kleppe 1,2,3,6, Ljiljana Vlatkovic ${ }^{4}$, Elin Ersvær ${ }^{1,3}$, Håkon Wæhre ${ }^{1,3}$, \\ Birgitte Nielsen ${ }^{1,3}$, Marte Avranden Kjær ${ }^{1,3}$, Manohar Pradhan ${ }^{1,3}$, Rolf Anders Syvertsen ${ }^{1,3}$, \\ John Arne Nesheim ${ }^{1,3}$, Knut Liestøl ${ }^{2,3}$, Fritz Albregtsen ${ }^{1,2}$ and Håvard E Danielsen ${ }^{\star 1,2,3,5}$ \\ ${ }^{1}$ Institute for Cancer Genetics and Informatics, Oslo University Hospital, Oslo NO-0424, Norway; ${ }^{2}$ Department of Informatics, \\ University of Oslo, Oslo NO-0316, Norway; ${ }^{3}$ Centre for Cancer Biomedicine, University of Oslo, Oslo NO-0424, Norway; \\ ${ }^{4}$ Department of Pathology, Oslo University Hospital, Oslo NO-0424, Norway and ${ }^{5}$ Nuffield Division of Clinical Laboratory Sciences, \\ University of Oxford, Oxford OX3 9DU, UK
}

Background: Pathological evaluations give the best prognostic markers for prostate cancer patients after radical prostatectomy, but the observer variance is substantial. These risk assessments should be supported and supplemented by objective methods for identifying patients at increased risk of recurrence. Markers of epigenetic aberrations have shown promising results in several cancer types and can be assessed by automatic analysis of chromatin organisation in tumour cell nuclei.

Methods: A consecutive series of 317 prostate cancer patients treated with radical prostatectomy at a national hospital between 1987 and 2005 were followed for a median of 10 years (interquartile range, 7-14). On average three tumour block samples from each patient were included to account for tumour heterogeneity. We developed a novel marker, termed Nucleotyping, based on automatic assessment of disordered chromatin organisation, and validated its ability to predict recurrence after radical prostatectomy.

Results: Nucleotyping predicted recurrence with a hazard ratio (HR) of 3.3 (95\% confidence interval (Cl), 2.1-5.1). With adjustment for clinical and pathological characteristics, the HR was $2.5(95 \% \mathrm{Cl}, 1.5-4.1)$. An updated stratification into three risk groups significantly improved the concordance with patient outcome compared with a state-of-the-art risk-stratification tool $(P<0.001)$. The prognostic impact was most evident for the patients who were high-risk by clinical and pathological characteristics and for patients with Gleason score 7.

Conclusion: A novel assessment of epigenetic aberrations was capable of improving risk stratification after radical prostatectomy.

Among European men, prostate cancer is the most commonly diagnosed and third most lethal cancer type (Ferlay et al, 2013). Randomised trials confirm that radical prostatectomy improves survival, at least for high-risk patients (Bill-Axelson et al, 2011; Wilt et al, 2012), and that radiation therapy or immediate hormonal therapy after radical prostatectomy may further reduce the risk of recurrence and death (Messing et al, 1999; Thompson et al, 2009). There is thus a need for identifying patients at high risk of recurrence in order to offer adjuvant treatment.

Clinical characteristics and pathological evaluations can be applied to estimate the risk of recurrence after radical prostatectomy. Gleason grading gives the currently best prognostic marker, but is subjective and has high observer variation (Melia et al, 2006; Bottke et al, 2013). Current risk-stratification tools incorporate a range of prognostic markers to obtain accurate prediction of cancer recurrence and mortality. One externally validated tool is Cancer of the Prostate Risk Assessment Postsurgical (CAPRA-S; Cooperberg et al, 2011; Punnen et al, 2014; Tilki et al, 2015), which combines preoperative PSA and pathological evaluations of Gleason score, surgical margins (SM), extracapsular extension (ECE), seminal vesicle invasion (SVI) and lymph node invasion (LNI). Objective methods that confirm and

*Correspondence: Professor HE Danielsen; E-mail: hdaniels@ifi.uio.no

${ }^{6}$ These authors are joint first authors with equal contribution.

Received 15 January 2016; revised 10 March 2016; accepted 15 March 2016; published online 28 April 2016 
supplement the prediction of such tools are desired, but are challenging to identify due to several properties of prostate cancer, including tumour heterogeneity and slow growth (Algaba and Montironi, 2010; Andreoiu and Cheng, 2010).

The aim of this study was to develop and validate a novel prognostic marker for recurrence after radical prostatectomy that could supplement current risk stratifications. The marker objectively assessed disordered chromatin organisation by analysing the texture in images of DNA-specifically stained cell nuclei, and was thus a measure of epigenetic aberrations. Similar markers have proven to offer substantial prognostic information for a wide range of malignancies, including prostate cancer (Jorgensen et al, 1996; Yogesan et al, 1996; Potter et al, 1999; Veltri et al, 2004; Mohamed et al, 2009). Unlike the most similar methods, our marker stratifies on regions defined by the distance to the nuclear periphery, as some genes and chromosome territories reposition radially during carcinogenesis (Cremer et al, 2003; Leshner et al, 2016). In addition, we focus on the smallest cell nuclei and account for heterogeneity and variations in imaging equipment. The marker, termed Nucleotyping, was integrated with CAPRA-S for improved risk stratification.

\section{PATIENTS AND METHODS}

Patient material. A consecutive series of 317 patients treated with radical prostatectomy at the Norwegian Radium Hospital during 1987 to 2005 was included in the study. The study was approved by the Regional Committees for Medical and Health Research Ethics (REK) in Norway (REK no. S-07443a). A total of 307 patients had available tumour material and were eligible for analysis. Median follow-up time was 10 years (interquartile range (IQR), 7-14). The primary end point was time to recurrence, defined in accordance with Punt et al (2007), and recurrence was assessed with biopsy, digital rectal examination or imaging modalities. Pathology of all study specimens were centrally reviewed by an experienced uropathologist (LV) who was blinded with respect to patient outcome, using the 2005 ISUP consensus and the ADASP practice guidelines (Epstein et al, 2005, 2008).

Tumour block sampling and selection. On average three tumour block samples (IQR, 3-4) were included for each patient in order to account for heterogeneity and the entailed sampling challenge. In DNA ploidy analysis, the patient was considered non-diploid if a non-diploid tumour block was sampled; otherwise, the patient was classified as diploid. This is in accordance with the DNA ploidy study by Pretorius et al (2009), which used a subset of the present sample and patient cohort. For Nucleotyping, we correspondingly represented the patient by the tumour block sample most indicative of recurrence (see Supplementary Methods).

Image cytometry. Monolayers of isolated cell nuclei stained with Feulgen-Schiff were prepared from formalin-fixed paraffinembedded tissue as described by Kristensen et al (2003). Images of cell nuclei and corresponding DNA contents were measured with a Zeiss Axioplan microscope equipped with a $546 \mathrm{~nm}$ green filter and a monochrome high-resolution digital camera (AxioCam MrM, Zeiss, Jena, Germany or C4742-95, Hamamatsu Photonics, Hamamatsu, Japan) and the Ploidy Work Station Grabber (Room4 Ltd, Crowborough, UK). Each pixel in the resulting images has a value, called the grey level, which reflects the local DNA density.

The imaged cell nuclei were automatically segmented and classified according to cell type by computer software. Trained personnel verified the cell classification and only epithelial cell nuclei were included for Nucleotyping, resulting in about 1400 nuclear images for each sample (IQR, 1000-1500).
Technical variation. The included samples were prepared over a 10 -year period. The microscopy system and sample preparation technique has been modified to some degree during these years, resulting in changed pixel resolution and image grey levels. The studied Nucleotyping method is founded on these attributes of the nuclear images and it is thus crucial that they are consistent across all samples in order to avoid occlusion of prognostic information.

In order to compensate for the technical dissimilarities, we normalised the size and grey levels of the nuclear images based on automatic detection of diploid cells in each sample, see Supplementary Methods for details. After normalisation, diploid cells in all samples had on average the same nuclear size and estimated amount of DNA.

Nucleotyping. The chromatin organisation in cell nuclei was automatically analysed by examining the spatial variations in DNA density within each nucleus. The observed spatial variations gave a single numerical value for each patient, termed the chromatin value, which was categorised into a two-group risk assessment of the patient.

For a given pixel in an image of a DNA-specifically stained cell nucleus, the spatial variation in DNA density was characterised by the entropy of the grey levels in the surrounding pixels. Entropy is a concept originating from thermodynamics, where it is used as a measure of disorder. In our context, it was applied to quantify the spatial disorder in DNA density. If the surrounding pixels have similar DNA densities, then the entropy will be low, while the entropy will be high in nuclear regions with diverse DNA densities. It is thus closely related to the organisation of euchromatin and heterochromatin in the nucleus and can be seen as a descriptor of either epigenetic phenotype or image texture.

The entropy in a nuclear region was paired with the grey level value at the region centre. This pair was computed for every pixel in the nuclear image, and a table was created to store the number of times each pair occurred; the procedure is illustrated in Supplementary Figure 1. This table gives the grey level entropy matrix (GLEM; Yogesan et al, 1996), which has shown diagnostic and prognostic significance (Jorgensen et al, 1996; Dunn et al, 2011; Nielsen et al, 2012, 2015).

Previous studies on texture analysis have shown that important diagnostic and prognostic information is found in the proximity of the nuclear periphery (Young et al, 1986; Nielsen et al, 1999, 2001; Wei et al, 2011). To include radially dependent information, we stratified the GLEM computation on each of five consecutive $10 \%$ radial regions of the nuclei (Supplementary Figure 2). Joining the GLEMs computed for each of these five radial regions resulted in a three-way table termed the radial GLEM (RGLEM); see Supplementary Methods for details. This table will describe DNA content and spatial variations in DNA density near the nuclear periphery.

Cell nuclei of widely different size have been shown to express distinct spatial variations in DNA density (Nielsen and Danielsen, 2006). Merging the characteristics of all nuclei may therefore degrade the prognostic ability, but can be dealt with by stratifying or selecting nuclei based on their size. Preliminary results led us to select the small nuclei ( $<2000$ pixels) for this study, or the $1 \%$ smallest nuclei for patients with no small nuclei (only one patient in the study cohort). Consequently, the RGLEM was calculated for about 80 (6\%) nuclei in each sample (IQR, 29-112).

An established algorithm was applied to obtain a single numerical value from the RGLEM of each tumour block sample, and the value most indicative of recurrence was automatically selected to represent the patient (see Supplementary Methods). The patient value was categorised into two outcome groups, representing either the indication of recurrence or the absence of such, using the conventional minimum Euclidean distance classification method where the patient is classified to the outcome group with 
most similar mean patient value (Duda et al, 2000). The patient grouping resulting from this procedure is hereafter referred to as the Nucleotyping classification. Figure 1 depicts the steps required to assess the Nucleotyping classification for a new patient.

Training and validating Nucleotyping. Computing the Nucleotyping classification requires a patient set because it applies an adaptive algorithm, that is, an algorithm that is automatically tuned to a patient cohort. The patients utilised to train a classifier cannot subsequently be applied to realistically evaluate its performance (Schulerud et al, 1998; Nielsen et al, 2008). We have therefore divided the patient material into a learning data set $(n=154)$ and a validation data set $(n=153)$ by systematically sampling every other patient after sorting by surgery date. The Nucleotyping classifier was adapted to the learning set and blindly applied to the validation set, providing an unbiased estimate of its predictive accuracy. Only a single classifier was validated, and thereby the multiple comparisons problem was avoided (Miller, 1981).

Repeated random sampling was applied to reliably estimate the expected validation performance of the Nucleotyping classifier (Michiels et al, 2005). The combined learning and validation set was randomly divided into new equally sized learning and validation sets (1000 repetitions). The Nucleotyping classifier was adapted to each resampled learning set, which is crucial to avoid overoptimism (Ambroise and McLachlan, 2002; Schulerud and Albregtsen, 2004), and evaluated in the corresponding, disjoint validation set.

DNA ploidy analysis. The grey level of a pixel is directly related to the DNA content at the pixel position. Adding the DNA content measurements of each nuclear pixel gives the total amount of DNA in the nucleus. This estimated DNA content of each cell in a tumour block sample was plotted as a histogram (see Supplementary Methods for details). Specially trained personnel classified these histograms as diploid, tetraploid or aneuploid according to specific criteria, see (Pretorius et al, 2009).

CAPRA-S. The CAPRA-S score is the sum of category points assigned to PSA, Gleason score, SM, ECE, SVI and LNI, and can be used directly or grouped at low (score 0-2), intermediate (score $3-5$ ) and high (score 6-12) risk of recurrence (Cooperberg et al, 2011). We integrated the Nucleotyping classification and the exact

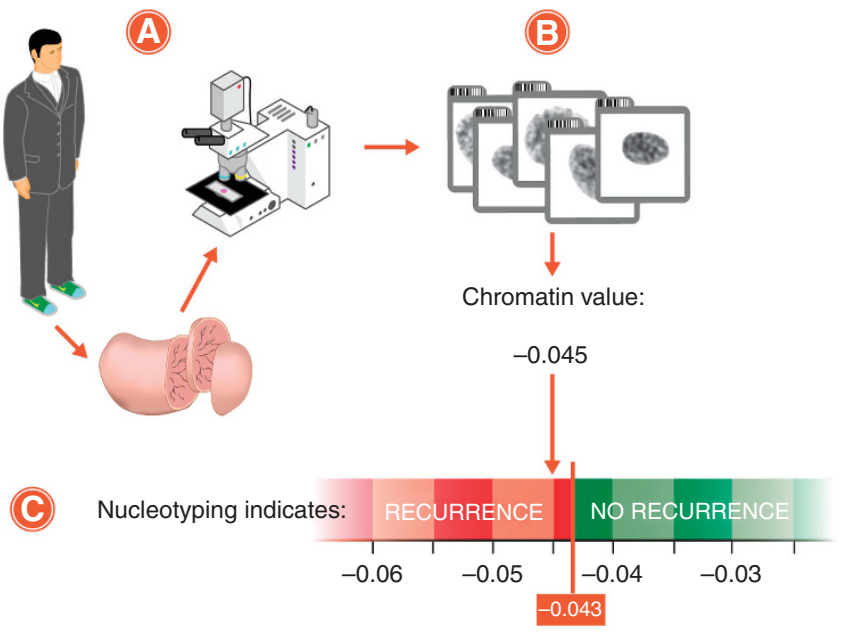

Figure 1. How to obtain the Nucleotyping classification of a prostate cancer patient. (A) After surgery, nuclei of the prostate cancer specimen are imaged. (B) Spatial variations in DNA density near the nuclear periphery are described by a single value, which is the chromatin value for the patient. (C) A fixed threshold is applied to obtain the estimated prognosis, either recurrence or no recurrence.
CAPRA-S score to obtain a Nucleotyping-pathological-classifier (NPC); based on the learning set, it was defined as the CAPRA-S score plus three if Nucleotyping indicated recurrence.

Statistical analyses. Recurrence was used as the end point in survival analysis, and time to recurrence was calculated from surgery to recurrence, death or 31 December 2008. The estimated survival functions were compared using Mantel-Cox' log-rank test in univariate analysis of categorical variables and Wald's $\chi^{2}$-test in univariate analysis of continuous variables and in multivariate analysis. The proportional hazards assumption was assessed using Schoenfeld residuals and found acceptable. The model's ability to predict patient outcome was measured with the concordance index by Harrell et al (1982), and the average optimism estimate from 10000 bootstrapped samples was applied to adjust the concordance index. Difference in concordance index between two models was assessed by the sign test on the bootstrapped samples. Decision curve analysis was performed to compare the net benefit of different models (Vickers and Elkin, 2006). Associations were evaluated using Pearson's $\chi^{2}$-test and Mann-Whitney's $U$-test. Patients with missing values for at least one included variable were excluded from the analysis. Statistical significance was defined as two-sided $P<0.05$. MATLAB 2012b (The MathWorks, Natick, MA, USA) was used for Nucleotyping, whereas survival analyses were carried out in Stata/SE 14.0 (StataCorp, College Station, TX, USA) and R v.3.1.3 (http://www.r-project.org).

\section{RESULTS}

Clinical and pathological characteristics of the studied patient cohort are summarised in Table 1 . Few patients (6\%) had low Gleason scores $(\leqslant 6)$ and the majority $(67 \%)$ had the intermediate Gleason score (7). All CAPRA-S scores were observed, but about half the patients $(49 \%)$ were high-risk, by CAPRA-S (score $\geqslant 6$ ). The vast majority of the analysed small nuclei were of diploid cells in G0 or G1 phase, but all cell cycle stages and ploidy types were represented (Supplementary Figure 3).

Nuclear texture analysis near the periphery of the smallest cell nuclei was significant for the validation cohort in univariate analysis $(P=0.004$; hazard ratio (HR) with $95 \%$ confidence interval $(\mathrm{CI})=2.3(1.3-4.1))$ and when stratified on each CAPRA-S score $(P=0.016$; HR $=2.3(1.2-4.6))$. Survival curves grouped by the Nucleotyping classification are shown in Supplementary Figure 4. The median (95\% CI) sensitivity, specificity and correct classification rate of our epigenetic marker were $70 \%(54-83 \%), 65 \%(55-74 \%)$ and $67 \%(59-73 \%)$ in repeated random sampling. Similarly, the classification accuracies were $73 \%$, $66 \%$ and $68 \%$ in the combined learning and validation set.

In the combined set, Nucleotyping was significant in univariate analysis $(P<0.001 ; \mathrm{HR}=3.3(2.1-5.1))$ and with adjustment for CAPRA-S $(P<0.001 ; \mathrm{HR}=2.5(1.5-4.1))$. The epigenetic marker and CAPRA-S showed low positive correlation (Spearman's $\rho=0.36, P<0.001)$. Medians (IQRs) for CAPRA-S and NPC were 5 (4-8) and 7 (4-10). Their concordance indices after bootstrap optimism adjustment were 0.76 and 0.78 , respectively, and the difference was significant in internal validation $(P<0.001)$.

Figure $2 \mathrm{~A}$ and $\mathrm{B}$ illustrate that our epigenetic marker substratified patients who were high-risk by clinical and pathological characteristics (CAPRA-S score $\geqslant 6: P=0.001, \mathrm{HR}=2.4$ (1.4-4.0)) and also patients at low or intermediate risk (CAPRA-S score $\leqslant 5: P=0.010, \mathrm{HR}=3.5(1.3-9.6))$. This additional prognostic information could be incorporated in an NPC riskstratification tool by letting Nucleotyping separate the intermediate- and high-risk CAPRA-S groups, as visualised in Figure 3. The bootstrap optimism-adjusted concordance index for the NPC risk groups was 0.75 , which was 0.045 higher than for the CAPRA-S 
Table 1. Characteristics of the studied patients

\begin{tabular}{|c|c|c|c|c|}
\hline $\begin{array}{l}\text { Patient } \\
\text { characteristics }\end{array}$ & $N$ & $\begin{array}{c}\text { No } \\
\text { recurrence, } \\
n(\%)\end{array}$ & $\begin{array}{c}\text { Recurrence, } \\
n(\%)\end{array}$ & $P$-value \\
\hline Study cohort & 307 & 207 & 100 & \\
\hline Nucleotyping & & & & $<0.001^{\mathrm{a}}$ \\
\hline $\begin{array}{l}\text { Indicated no recurrence } \\
\text { Indicated recurrence }\end{array}$ & $\begin{array}{l}164 \\
143\end{array}$ & $\begin{array}{r}137(66) \\
70(34)\end{array}$ & $\begin{array}{l}27(27) \\
73(73)\end{array}$ & \\
\hline DNA ploidy & & & & $<0.001^{\mathrm{a}}$ \\
\hline $\begin{array}{l}\text { Diploid } \\
\text { Non-diploid }\end{array}$ & $\begin{array}{l}180 \\
127\end{array}$ & $\begin{aligned} 135(65) \\
72(35) \\
\end{aligned}$ & $\begin{array}{l}45(45) \\
55(55)\end{array}$ & \\
\hline CAPRA-S risk group & & & & $<0.001^{a}$ \\
\hline $\begin{array}{l}\text { Low (0-2) } \\
\text { Intermediate (3-5) } \\
\text { High (6-12) }\end{array}$ & $\begin{array}{c}46 \\
108 \\
147\end{array}$ & $\begin{array}{l}45(22) \\
92(45) \\
68(33)\end{array}$ & $\begin{array}{c}1(1) \\
16(17) \\
79(82)\end{array}$ & \\
\hline Age, years & & & & $0.84^{b}$ \\
\hline $\begin{array}{l}\text { Median } \\
\text { IQR }\end{array}$ & $\begin{array}{c}63 \\
58-67\end{array}$ & $\begin{array}{c}63 \\
58-67\end{array}$ & $\begin{array}{c}63 \\
58-68\end{array}$ & \\
\hline $\begin{array}{l}\text { Preoperative PSA, } \\
\mathrm{ng} \mathrm{ml}^{-1}\end{array}$ & & & & $<0.001^{\mathrm{a}}$ \\
\hline $\begin{array}{l}\leqslant 6 \\
>6 \text { and } \leqslant 10 \\
>10 \text { and } \leqslant 20 \\
>20\end{array}$ & $\begin{array}{l}79 \\
62 \\
93 \\
70\end{array}$ & $\begin{array}{l}66(32) \\
54(26) \\
52(25) \\
35(17)\end{array}$ & $\begin{array}{c}13(13) \\
8(8) \\
41(42) \\
35(36)\end{array}$ & \\
\hline Gleason score & & & & $<0.001^{\mathrm{a}}$ \\
\hline $\begin{array}{l}\leqslant 6 \\
3+4 \\
4+3 \\
\geqslant 8\end{array}$ & $\begin{array}{c}18 \\
118 \\
88 \\
83\end{array}$ & $\begin{aligned} 17(8) \\
105(51) \\
57(28) \\
28(14)\end{aligned}$ & $\begin{array}{c}1(1) \\
13(13) \\
31(31) \\
55(55)\end{array}$ & \\
\hline SM & & & & $<0.001^{a}$ \\
\hline $\begin{array}{l}\text { Negative } \\
\text { Positive }\end{array}$ & $\begin{array}{l}119 \\
188\end{array}$ & $\begin{array}{r}96(46) \\
111(54)\end{array}$ & $\begin{array}{l}23(23) \\
77(77)\end{array}$ & \\
\hline ECE & & & & $<0.001^{\mathrm{a}}$ \\
\hline $\begin{array}{l}\text { Absent } \\
\text { Present }\end{array}$ & $\begin{array}{c}78 \\
226\end{array}$ & $\begin{array}{r}71(35) \\
134(65)\end{array}$ & $\begin{array}{c}7(7) \\
92(93)\end{array}$ & \\
\hline SVI & & & & $<0.001^{\mathrm{a}}$ \\
\hline $\begin{array}{l}\text { Absent } \\
\text { Present }\end{array}$ & $\begin{array}{c}238 \\
69\end{array}$ & $\begin{array}{r}182(88) \\
25(12)\end{array}$ & $\begin{array}{l}56(56) \\
44(44)\end{array}$ & \\
\hline LNI & & & & $0.004^{a}$ \\
\hline $\begin{array}{l}\text { Absent } \\
\text { Present }\end{array}$ & $\begin{array}{c}292 \\
15\end{array}$ & $\begin{array}{l}202(98) \\
5(2)\end{array}$ & $\begin{array}{l}90(90) \\
10(10)\end{array}$ & \\
\hline Follow-up time, months & & & & $0.010^{b}$ \\
\hline $\begin{array}{l}\text { Median } \\
\text { IQR }\end{array}$ & $\begin{array}{c}126 \\
88-171\end{array}$ & $\begin{array}{c}117 \\
84-168\end{array}$ & $\begin{array}{c}148 \\
105-174 \\
\end{array}$ & \\
\hline \multicolumn{5}{|c|}{$\begin{array}{l}\text { Abbreviations: CAPRA-S }=\text { Cancer of the Prostate Risk Assessment Postsurgical; } \\
E C E=\text { extracapsular extension; } \quad \mid Q R=\text { interquartile range; } L N I=\text { lymph node invasion; } \\
\text { PSA = prostate-specific antigen; } S M=\text { surgical margins; } S V I=\text { seminal vesicle invasion. } \\
{ }^{a} \text { Pearson's } \chi^{2} \text {-test. } \\
\text { b }_{\text {Mann-Whitney's U-test. }}\end{array}$} \\
\hline
\end{tabular}

risk groups $(P<0.001)$. Figure $4 \mathrm{~A}$ displays the increased net benefit of the NPC risk stratification.

The prognostic impact of Nucleotyping within each Gleason category is shown in Figure 2C-F. Besides the small group of patients with Gleason score $\leqslant 6$ which consisted of 18 patients, only one with recurrence, the epigenetic marker provided additional prognostic information in each Gleason category with significance for Gleason score $3+4$ and $4+3$.

DNA ploidy was statistically significant in univariate analysis $(P=0.010 ; \mathrm{HR}=1.7(1.1-2.5))$, but not when stratified on each CAPRA-S score $(P=0.83 ; \mathrm{HR}=0.95(0.61-1.48))$. Nucleotyping was able to identify patients at increased risk of recurrence in each DNA ploidy group (Figure $2 \mathrm{G}$ and $\mathrm{H}$ ). Univariate and multivariate analysis of all candidate markers are shown in Supplementary Table 1.

Patients with Gleason score 7. Nucleotyping was significant among patients with Gleason score 7 with adjustment for CAPRA$S$ (validation: $P=0.006, \mathrm{HR}=4.3 \quad(1.4-13.1)$; combined set: $P=0.002, \mathrm{HR}=2.9$ (1.4-5.8)). The bootstrap optimism-adjusted concordance index for the NPC score was 0.77 in this subgroup of the combined set, compared with 0.74 for the CAPRA-S score, a difference which was significant $(P<0.001)$. Correspondingly, the three NPC risk groups gave a concordance index of 0.75 , while the CAPRA-S risk groups gave a significantly lower index of 0.71 $(P<0.001)$. The NPC risk stratification improved the net benefit compared with the three CAPRA-S risk groups (Figure 4B).

Heterogeneity analysis. In total, 199 (19\%) tumour block samples indicated recurrence according to Nucleotyping; for any given patient, at most four samples indicated recurrence (Supplementary Figure 5). No samples indicated recurrence in 164 (53\%) patients, which were the patients Nucleotyping classified as not recurring. Although the epigenetic marker correctly identified $73 \%$ of the recurring patients, only $31 \%$ of their samples indicated recurrence. Typically, Nucleotyping indicated patient recurrence because of a single tumour block sample, but multiple samples indicating recurrence correlated with worse patient outcome (one $v s$ multiple samples indicating recurrence: $P=0.006, \mathrm{HR}=1.9$ (1.2-3.0); Supplementary Figure 6).

Sensitivity analyses. The prognostic value of Nucleotyping was robust to alterations in the applied definition of small cell nuclei and changes in number of analysed cells (Supplementary Figure 7). In addition, the epigenetic marker was a significant predictor of metastasis $(P=0.003, \mathrm{HR}=2.4(1.3-4.3))$ and cancer-specific survival $(P=0.013, \mathrm{HR}=2.6(1.2-5.9))$.

\section{DISCUSSION}

Nucleotyping by texture analysis near the periphery of small cell nuclei was an independent prognostic marker in prostate cancer in both validation and the combined learning and validation set. The expected validation performance measured by repeated random sampling was similar to the performance in the combined set, justifying the application of the combined set for analysis.

Our novel epigenetic marker significantly enhanced CAPRA-S both as score and as three-grouped risk stratification. The integrated model was superior to CAPRA-S, demonstrated by significantly increased concordance with patient outcome and improved net benefit (Figure 4). In particular, there was strong evidence for improved prediction of recurrence for patients at high-risk by clinical and pathological characteristics (CAPRA-S score $\geqslant 6$; Figure $2 \mathrm{~A}$ ).

Even when centrally reviewed by an experienced uropathologist, Nucleotyping substratified patients with intermediate Gleason score, either $3+4$ or $4+3$ (Figure 2D and E). Merging Nucleotyping with the three CAPRA-S risk groups markedly augmented the predication accuracy for these patients, increasing the concordance index from 0.71 to 0.75 and amplified the net benefit. Proper identification of low-risk patients with Gleason score 7 tumours is challenging, but important, as illustrated by the difficulties in distinguishing Gleason score $3+4$ patterns from $4+3$ and the debate on including Gleason score $3+4$ patients in active surveillance programs. Our epigenetic marker thus meets a particular need for improved prognostication in this patient subgroup.

DNA ploidy analysis has been shown to provide prognostic information in prostate cancer (Pretorius et al, 2009; Böcking et al, 2014; Danielsen et al, 2016). In this patient series, we found DNA 
A
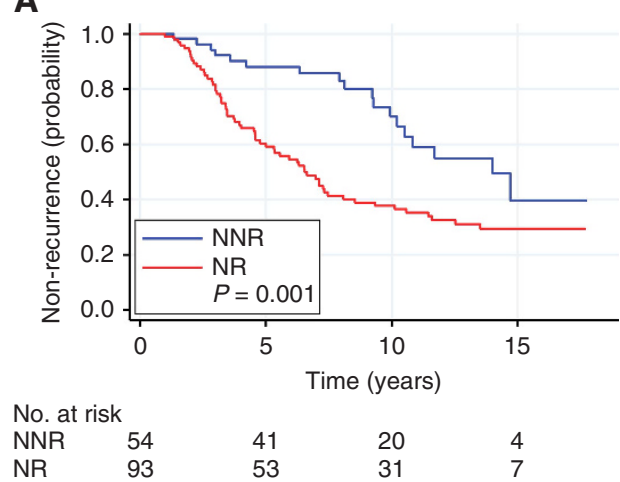

C

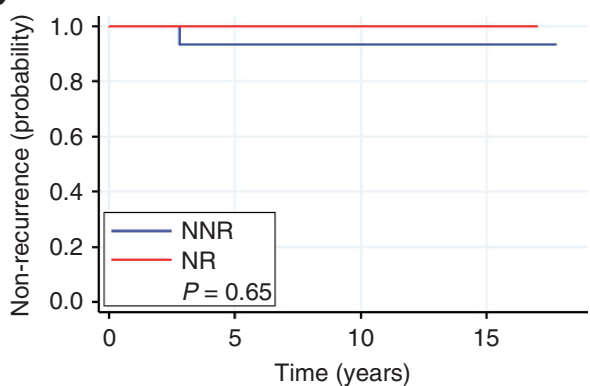

No. at risk

$\begin{array}{lcccc}\text { NNR } & 15 & 12 & 5 & 2 \\ \text { NR } & 3 & 3 & 3 & 2\end{array}$

E

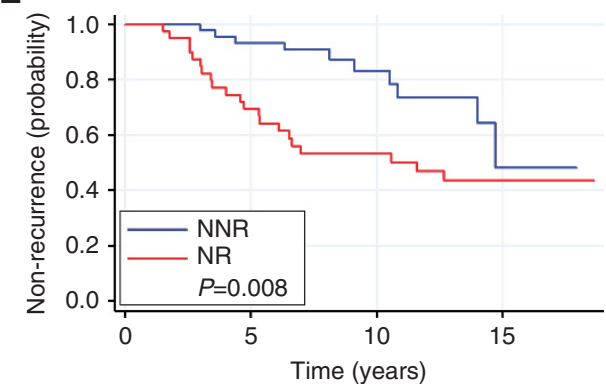

$\begin{array}{lllll}\text { No. at risk } & & & & \\ \text { NNR } & 47 & 40 & 18 & 3 \\ \text { NR } & 41 & 27 & 18 & 6\end{array}$

G

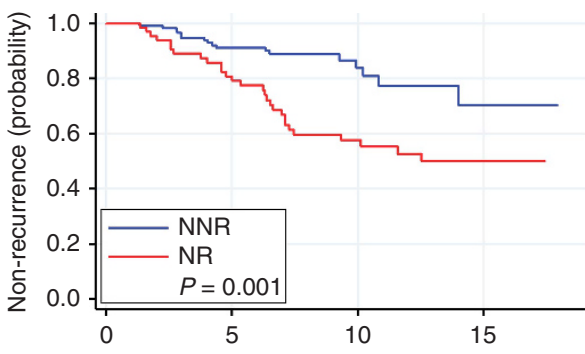

No. at risk

$\begin{array}{ll}\text { NNR } & 114 \\ \text { NR } & 66\end{array}$
Time (years)

93

30
7
B

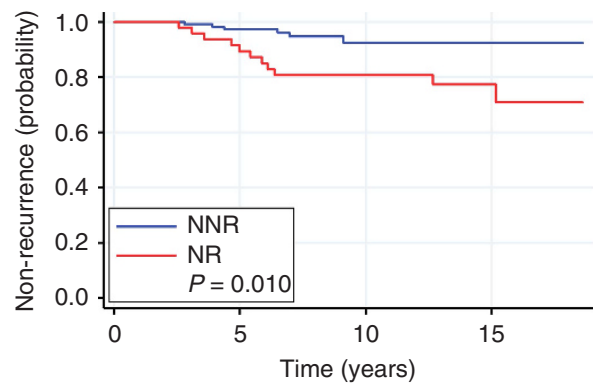

No. at risk

$\begin{array}{lcccc}\text { NNR } & 106 & 93 & 31 & 7 \\ \text { NR } & 48 & 41 & 27 & 12\end{array}$

D

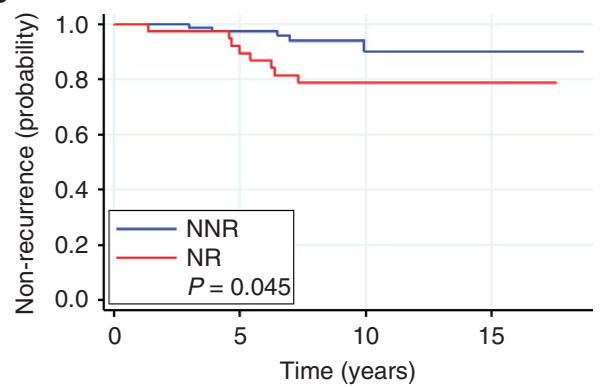

No. at risk

$\begin{array}{lllll}\text { NNR } & 79 & 69 & 22 & 5 \\ \text { NR } & 39 & 34 & 21 & 9\end{array}$

F

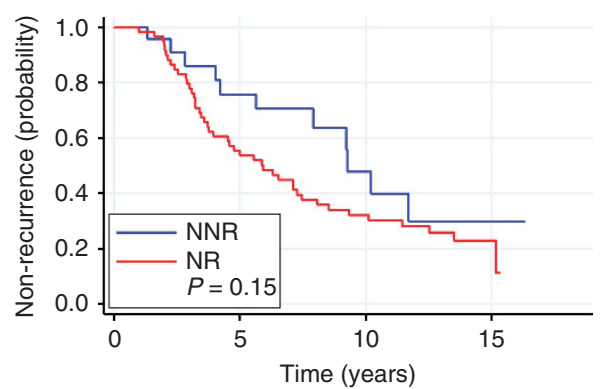

No. at risk

$\begin{array}{llccc}\text { NNR } & 23 & 15 & 6 & 1 \\ \text { NR } & 60 & 31 & 17 & 3\end{array}$

H

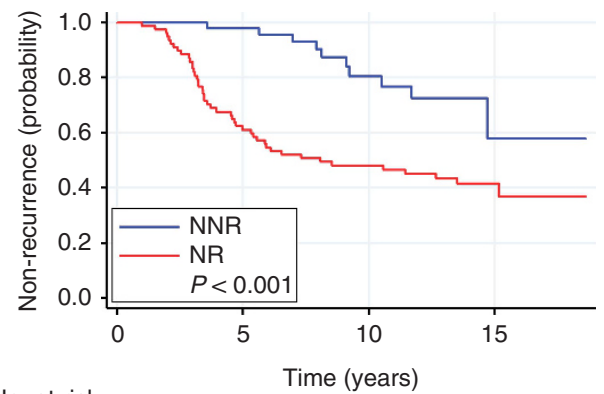

No. at risk

$\begin{array}{llllc}\text { NNR } & 50 & 43 & 21 & 4 \\ \text { NR } & 77 & 47 & 34 & 10\end{array}$

Figure 2. Kaplan-Meier curves of recurrence probability after radical prostatectomy grouped by Nucleotyping. (A) Patients with high CAPRA-S (score $\geqslant 6$ ). (B) Patients with low or intermediate CAPRA-S (score $\leqslant 5$ ). (C) Patients with low Gleason score $(\leqslant 6)$. (D) Patients with Gleason score $3+4$. (E) Patients with Gleason score $4+3$. (F) Patients with high Gleason score ( $\geqslant 8$ ). (G) Patients with diploid DNA ploidy type. (H) Patients with non-diploid DNA ploidy type. Abbreviations: CAPRA-S = Cancer of the Prostate Risk Assessment Postsurgical; NNR= Nucleotyping indicated no recurrence; $N R=$ Nucleotyping indicated recurrence. 


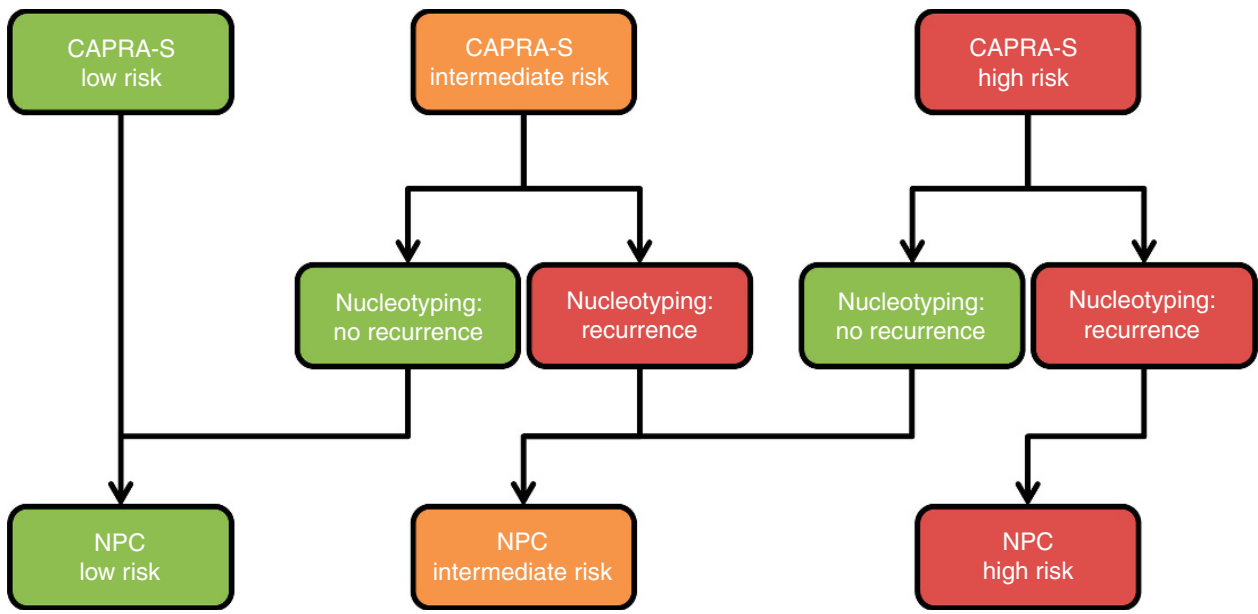

Figure 3. Flowchart illustrating the definition of the three NPC risk groups. Abbreviations: CAPRA-S $=$ Cancer of the Prostate Risk Assessment Postsurgical; NPC = Nucleotyping-pathological-classifier.
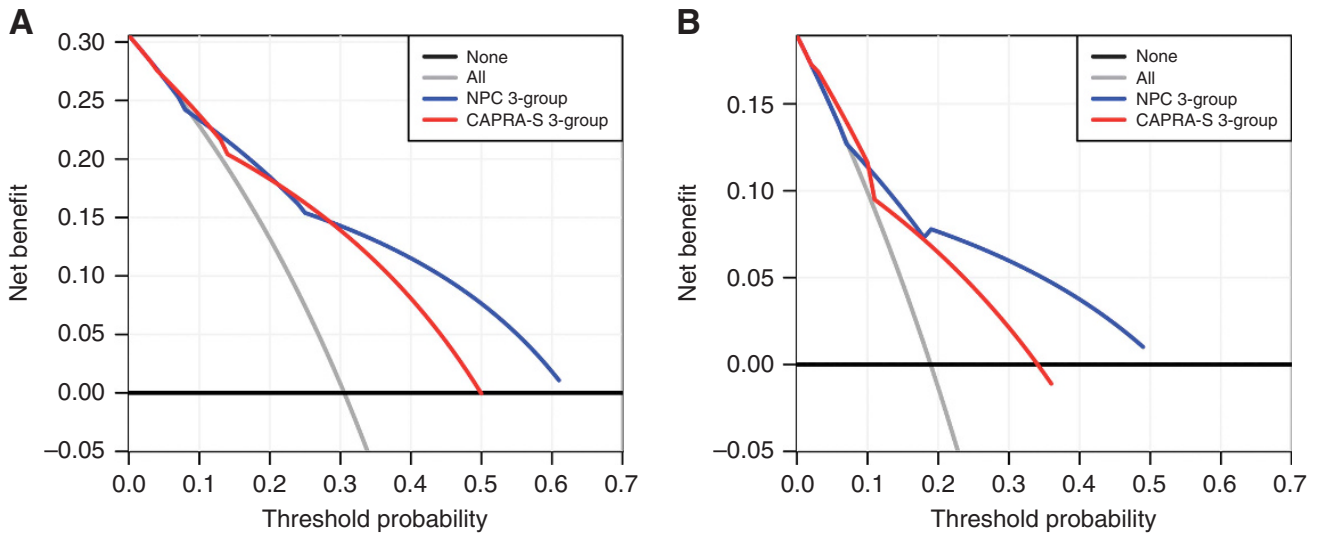

Figure 4. Survival decision curves for predicting 10-year post-radical prostatectomy time to recurrence (TTR) for (A) all patients and (B) patients with Gleason score 7. CAPRA-S and NPC, both grouped in three risk groups, were converted into 10-year TTR probabilities before estimating net benefit. The integrated model demonstrates a higher net benefit. Abbreviations: CAPRA-S 3-group =the three Cancer of the Prostate Risk Assessment Postsurgical risk groups; NPC 3-group=the three Nucleotyping-pathological-classifier risk groups.

ploidy to be a significant prognostic marker in univariate analysis and that Nucleotyping provides additional information and is an even stronger prognostic marker (Figure $2 \mathrm{G}$ and H; Supplementary Table 1).

Marked heterogeneity was observed in our patient cohort. Among the recurring patients, only $31 \%$ of their samples had epigenetic characteristics indicating recurrence even though Nucleotyping correctly classified $73 \%$ of them. The risk of patient recurrence gradually increased with the number of samples indicating recurrence according to our epigenetic marker (Supplementary Figures 5 and 6), suggesting that the presence of similar epigenetic aberrations at multiple foci correlates with a more advanced disease. Further investigations are warranted to validate this prognostic trend and identify its mechanistic foundation.

Robustness is essential for a clinically applicable prognostic marker. The studied small cell nuclei constituted only $6 \%$ of all epithelial nuclei. Sensitivity analyses showed that Nucleotyping was robust to changes in number and size of analysed nuclei (Supplementary Figure 7). Moreover, the epigenetic marker delineated the patient outcome in analyses of time to metastasis and cancer-specific survival, demonstrating that the marker also correlates with later and harder oncologic endpoints.

The observed DNA density patterns in the proximity of the nuclear periphery (data not shown) were in accordance with observations by Nielsen et al (2001) in early ovarian cancer.
Patients with recurrence were associated with decreased DNA density near the periphery of the nuclei and increased DNA density in the nuclear interior. As peripheral chromatin is typically more condensed in normal cell nuclei than interior chromatin, this agrees with observations that the radial arrangement is reduced in tumour cell nuclei (Cremer et al, 2003; Zuleger et al, 2011).

Although it is preferable that only a single tumour block sample is applied to assert a biomarker, the heterogeneity in prostate cancer implies that multiple sampling may be essential to obtain the best prognostication. Indeed, most pathological assessments, including Gleason grading, utilise all samples and we have therefore applied multiple samples to assess the Nucleotyping classification.

Extensive PSA testing in recent years has led to earlier diagnosis and the discovery of disease that would previously not have been detected. Current prostate cancer patients thus have fewer and later recurrences and less aggressive clinical and pathological characteristics. The majority of patients included in this study were diagnosed prior to extensive PSA testing. The high recurrence rate and long follow-up in the present patient cohort makes it particularly applicable to analyse more advanced prostate cancer patients by today's standard.

In conclusion, Nucleotyping by texture analysis near the periphery of the smallest cell nuclei is an objective and independent prognostic marker in prostate cancer. It was integrated 
with CAPRA-S and then significantly enhanced the risk-stratification of patients treated with radical prostatectomy. The improvement was most distinct for patients with high-risk CAPRA-S scores and for patients with Gleason score 7. Nucleotyping may therefore be applicable for treatment management of prostate cancer patients. An independent multicentre trial to validate the prognostic impact is warranted.

\section{ACKNOWLEDGEMENTS}

We thank Marna Lill Kjæreng for technical assistance, Marian Seiergren for creating Figure 1 and Supplementary Figure 1, and the reviewers and editors of the British Journal of Cancer for valuable suggestions. This work was supported by the Helse Sør-Øst research fund (project number 2015070).

\section{CONFLICT OF INTEREST}

The authors declare no conflict of interest.

\section{REFERENCES}

Algaba F, Montironi R (2010) Impact of prostate cancer multifocality on its biology and treatment. J Endourol 24(5): 799-804.

Ambroise C, McLachlan GJ (2002) Selection bias in gene extraction on the basis of microarray gene-expression data. Proc Natl Acad Sci USA 99(10): 6562-6566.

Andreoiu M, Cheng L (2010) Multifocal prostate cancer: biologic, prognostic, and therapeutic implications. Hum Pathol 41(6): 781-793.

Bill-Axelson A, Holmberg L, Ruutu M, Garmo H, Stark JR, Busch C, Nordling S, Häggman M, Andersson S-O, Bratell S, Spångberg A, Palmgren J, Steineck G, Adami H-O, Johansson J-E (2011) Radical prostatectomy versus watchful waiting in early prostate cancer. $\mathrm{N} \mathrm{Engl} J$ Med 364(18): 1708-1717.

Böcking A, Tils M, Schramm M, Dietz J, Biesterfeld S (2014) DNA-cytometric grading of prostate cancer Systematic review with descriptive data analysis. Pathol Discov 2(7).

Bottke D, Golz R, Storkel S, Hinke A, Siegmann A, Hertle L, Miller K, Hinkelbein W, Wiegel T (2013) Phase 3 study of adjuvant radiotherapy versus wait and see in $\mathrm{pT} 3$ prostate cancer: impact of pathology review on analysis. Eur Urol 64(2): 193-198.

Cooperberg MR, Hilton JF, Carroll PR (2011) The CAPRA-S score: a straightforward tool for improved prediction of outcomes after radical prostatectomy. Cancer 117(22): 5039-5046.

Cremer M, Kupper K, Wagler B, Wizelman L, von Hase J, Weiland Y, Kreja L, Diebold J, Speicher MR, Cremer T (2003) Inheritance of gene densityrelated higher order chromatin arrangements in normal and tumor cell nuclei. J Cell Biol 162(5): 809-820.

Danielsen HE, Pradhan M, Novelli M (2016) Revisiting tumour aneuploidythe place of ploidy assessment in the molecular era. Nat Rev Clin Oncol 13(5): 291-304.

Duda RO, Hart PE, Stork DG (2000) Discriminant functions for the normal density. In Pattern Classification, 2nd edn, Chapter 2.6, pp 36-45. John Wiley \& Sons: New York, NY, USA.

Dunn JM, Hveem T, Pretorius M, Oukrif D, Nielsen B, Albregtsen F, Lovat LB, Novelli MR, Danielsen HE (2011) Comparison of nuclear texture analysis and image cytometric DNA analysis for the assessment of dysplasia in Barrett's oesophagus. Br J Cancer 105(8): 1218-1223.

Epstein JI, Allsbrook Jr WC, Amin MB, Egevad LL (2005) The 2005 International Society of Urological Pathology (ISUP) Consensus Conference on Gleason Grading of Prostatic Carcinoma. Am J Surg Pathol 29(9): 1228-1242.

Epstein JI, Srigley J, Grignon D, Humphrey P. Association of Directors of Anatomic and Surgical Pathology (2008) Recommendations for the reporting of prostate carcinoma. Am J Clin Pathol 129(1): 24-30.

Ferlay J, Steliarova-Foucher E, Lortet-Tieulent J, Rosso S, Coebergh JW, Comber H, Forman D, Bray F (2013) Cancer incidence and mortality patterns in Europe: estimates for 40 countries in 2012. Eur J Cancer 49(6): 1374-1403.

Harrell Jr FE, Califf RM, Pryor DB, Lee KL, Rosati RA (1982) Evaluating the yield of medical tests. JAMA 247(18): 2543-2546.

Jorgensen T, Yogesan K, Tveter KJ, Skjorten F, Danielsen HE (1996) Nuclear texture analysis: a new prognostic tool in metastatic prostate cancer. Cytometry 24(3): 277-283.

Kristensen GB, Kildal W, Abeler VM, Kaern J, Vergote I, Trope CG, Danielsen HE (2003) Large-scale genomic instability predicts long-term outcome for women with invasive stage I ovarian cancer. Ann Oncol 14(10): 1494-1500.

Leshner M, Devine M, Roloff GW, True LD, Misteli T, Meaburn KJ (2016) Locus-specific gene repositioning in prostate cancer. Mol Biol Cell 27(2): 236-246.

Melia J, Moseley R, Ball RY, Griffiths DF, Grigor K, Harnden P, Jarmulowicz M, McWilliam LJ, Montironi R, Waller M, Moss S, Parkinson MC (2006) A UK-based investigation of inter- and intra-observer reproducibility of Gleason grading of prostatic biopsies. Histopathology 48(6): 644-654.

Messing EM, Manola J, Sarosdy M, Wilding G, Crawford ED, Trump D (1999) Immediate hormonal therapy compared with observation after radical prostatectomy and pelvic lymphadenectomy in men with node-positive prostate cancer. $N$ Engl J Med 341(24): 1781-1788.

Michiels S, Koscielny S, Hill C (2005) Prediction of cancer outcome with microarrays: a multiple random validation strategy. Lancet 365(9458): 488-492.

Miller RG (1981) Simultaneous Statistical Inference, 2nd edn. Springer-Verlag: New York, NY, USA.

Mohamed M, Greif PA, Diamond J, Sharafeldin O, Maxwell P, Montironi R, O’Brien A, Young M, Hamilton PW (2009) Changes in chromatin phenotype predict the response to hormonal deprivation therapy in patients with prostate cancer. BJU Int 103(3): 391-398.

Nielsen B, Albregtsen F, Danielsen HE (1999) The use of fractal features from the periphery of cell nuclei as a classification tool. Anal Cell Pathol 19(1): 21-37.

Nielsen B, Albregtsen F, Danielsen HE (2008) Statistical nuclear texture analysis in cancer research: a review of methods and applications. Crit Rev Oncog 14(2-3): 89-164.

Nielsen B, Albregtsen F, Kildal W, Abeler VM, Kristensen GB, Danielsen HE (2012) The prognostic value of adaptive nuclear texture features from patient gray level entropy matrices in early stage ovarian cancer. Anal Cell Pathol 35(4): 305-314.

Nielsen B, Albregtsen F, Kildal W, Danielsen HE (2001) Prognostic classification of early ovarian cancer based on very low dimensionality adaptive texture feature vectors from cell nuclei from monolayers and histological sections. Anal Cell Pathol 23(2): 75-88.

Nielsen B, Danielsen HE (2006) Prognostic value of adaptive textural features-the effect of standardizing nuclear first-order gray level statistics and mixing information from nuclei having different area. Cell Oncol 28(3): 85-95.

Nielsen B, Hveem TS, Kildal W, Abeler VM, Kristensen GB, Albregtsen F, Danielsen HE (2015) Entropy-based adaptive nuclear texture features are independent prognostic markers in a total population of uterine sarcomas. Cytometry A 87: 315-325.

Potter SR, Miller MC, Mangold LA, Jones KA, Epstein JI, Veltri RW, Partin AW (1999) Genetically engineered neural networks for predicting prostate cancer progression after radical prostatectomy. Urology 54(5): 791-795.

Pretorius ME, Waehre H, Abeler VM, Davidson B, Vlatkovic L, Lothe RA, Giercksky KE, Danielsen HE (2009) Large scale genomic instability as an additive prognostic marker in early prostate cancer. Cell Oncol 31(4): 251-259.

Punnen S, Freedland SJ, Presti Jr JC, Aronson WJ, Terris MK, Kane CJ, Amling CL, Carroll PR, Cooperberg MR (2014) Multi-institutional validation of the CAPRA-S score to predict disease recurrence and mortality after radical prostatectomy. Eur Urol 65(6): $1171-1177$

Punt CJ, Buyse M, Kohne CH, Hohenberger P, Labianca R, Schmoll HJ, Pahlman L, Sobrero A, Douillard JY (2007) Endpoints in adjuvant treatment trials: a systematic review of the literature in colon cancer and proposed definitions for future trials. J Natl Cancer Inst 99(13): 998-1003. 
Schulerud H, Albregtsen F (2004) Many are called, but few are chosen. Feature selection and error estimation in high dimensional spaces. Comput Methods Programs Biomed 73(2): 91-99.

Schulerud H, Kristensen GB, Liestol K, Vlatkovic L, Reith A, Albregtsen F, Danielsen HE (1998) A review of caveats in statistical nuclear image analysis. Anal Cell Pathol 16(2): 63-82.

Thompson IM, Tangen CM, Paradelo J, Lucia MS, Miller G, Troyer D, Messing E, Forman J, Chin J, Swanson G, Canby-Hagino E, Crawford ED (2009) Adjuvant radiotherapy for pathological T3N0M0 prostate cancer significantly reduces risk of metastases and improves survival: long-term followup of a randomized clinical trial. J Urol 181(3): 956-962.

Tilki D, Mandel P, Schlomm T, Chun FK, Tennstedt P, Pehrke D, Haese A, Huland H, Graefen M, Salomon G (2015) External validation of the CAPRA-S score to predict biochemical recurrence, metastasis and mortality after radical prostatectomy in a european cohort. J Urol 193(6): 1970-1975.

Veltri RW, Khan MA, Miller MC, Epstein JI, Mangold LA, Walsh PC, Partin AW (2004) Ability to predict metastasis based on pathology findings and alterations in nuclear structure of normal-appearing and cancer peripheral zone epithelium in the prostate. Clin Cancer Res 10(10): 3465-3473.
Vickers AJ, Elkin EB (2006) Decision curve analysis: a novel method for evaluating prediction models. Med Decis Making 26(6): 565-574.

Wei W, Ozolek JA, Slepčev D, Lee AB, Cheng C, Rohde GK (2011) An optimal transportation approach for nuclear structure-based pathology. IEEE Trans Med Imaging 30(3): 621-631.

Wilt TJ, Brawer MK, Jones KM, Barry MJ, Aronson WJ, Fox S, Gingrich JR, Wei JT, Gilhooly P, Grob BM, Nsouli I, Iyer P, Cartagena R, Snider G, Roehrborn C, Sharifi R, Blank W, Pandya P, Andriole GL, Culkin D, Wheeler T (2012) Radical prostatectomy versus observation for localized prostate cancer. N Engl J Med 367(3): 203-213.

Yogesan K, Jorgensen T, Albregtsen F, Tveter KJ, Danielsen HE (1996) Entropy-based texture analysis of chromatin structure in advanced prostate cancer. Cytometry 24(3): 268-276.

Young IT, Verbeek PW, Mayall BH (1986) Characterization of chromatin distribution in cell nuclei. Cytometry 7(5): 467-474.

Zuleger N, Robson MI, Schirmer EC (2011) The nuclear envelope as a chromatin organizer. Nucleus 2(5): 339-349.

(c) (i) (3) (2) This work is licensed under the Creative Commons Attribution-Non-Commercial-Share Alike 4.0 International License. To view a copy of this license, visit http:// creativecommons.org/licenses/by-nc-sa/4.0/

Supplementary Information accompanies this paper on British Journal of Cancer website (http://www.nature.com/bjc) 